\title{
"Sicca Complex" in Liver Disease
}

\author{
P. L. GOLDING, ${ }^{*}$ M.B., M.R.C.P. ; R. BOWN, $\dagger$ M.B., M.R.C.P. ; A. M. S. MASON, $\ddagger$ M.B., M.R.C.P. \\ E. TAYLOR, $\oint$ F.R.C.S., D.o.
}

British Medical fournal, 1970, 4, 340-342

Summary: Sixty-three patients with liver disease were $S$ studied for the presence of the components of Sjögren's syndrome. The "sicca complex" (that is, patients without arthritis) was detected in $42 \%$ of patients with active chronic hepatitis, $72 \%$ with primary biliary cirrhosis, and $38 \%$ with cryptogenic cirrhosis. One patient with active chronic hepatitis and one with primary biliary cirrhosis had rheumatoid arthritis. No evidence of Sjögren's syndrome was detected in seven patients with alcoholic cirrhosis. It is suggested that the sicca complex and autoimmune liver disease may be part of a systemic disorder in which immunological mechanisms are concerned in the pathogenesis.

\section{Introduction}

Sjögren (1933) described the triad of keratoconjunctivitis sicca, xerostomia, and rheumatoid arthritis. Bloch et al. (1965) divided the syndrome into five groups, the fifth of which comprises those cases without arthritis, having the "sicca complex" alone. Patients with and without arthritis commonly have hyperglobulinaemia and non-organ-specific autoantibodies in the serum (Bertram and Halberg, 1965; Bloch et al., 1965), and autoimmune processes are thought to be involved in the pathogenesis of the disorder (Heaton, 1959).

Active chronic hepatitis, primary biliary cirrhosis, and cryptogenic cirrhosis are the liver disorders commonly associated with hyperglobulinaemia and non-organ-specific autoantibodies (Doniach et al., 1966; Hobbs, 1970). Immunological mechanisms are probably concerned in their pathogenesis, and Doniach and Walker (1969) introduced the general term "autoimmune liver disease" to include these three hepatic disorders.

Sporadic reports of the concurrence of Sjögren's syndrome and autoimmune liver disease have suggested that the two disorders may be associated, and Whaley et al. (1970) found evidence of autoimmune liver disease in $6 \%$ of cases with the "sicca complex." As patients with liver disease may complain of dryness of the eyes and mouth, we have studied groups of patients with different hepatic disorders to determine the prevalence of the sicca complex and rheumatoid arthritis in them.

\section{Patients and Methods}

Sixty-three patients currently attending hospital were investigated. The liver function tests done were the concentrations of serum bilirubin, aspartate aminotransferase, alkaline phosphatase, albumin, and total globulin. A liver biopsy was obtained in all cases. Autoantibodies were detected by an immunofluorescent method using a 1:10 dilution of the patient's serum. A slide screening test for rheumatoid factor was performed with Rheumatex. The serum immunoglobulins IgG, IgA, and IgM were measured quantitatively by the single radial immunodiffusion method on an Immunoplate

\footnotetext{
* Senior Registrar, Division of Medicine, the London Hospital, London E.1.

† Research Registrar, Department of Gastroenterology, St. Bartholomew's Hospital, London E.C.1.

‡ Formerly Research Assistant, Southampton General Hospital, Southampton.

S Senior Registrar, Department of Ophthalmology, St. Bartholomew's Hospital, London E.C.1.
}

with the standards supplied by the manufacturer (Baxter \& Co., Thetford).

The patients were classified into four groups on the basis of clinical, biochemical, and histological criteria. Group 1 comprised 24 patients with active chronic hepatitis, of whom 2.2 were women, their ages ranging from 20 to 80 (mean 51) years. Group 2 comprised 18 patients with primary biliary cirrhosis, of whom 17 were women, their ages ranging from 46 to 69 (mean 55) years. Group 3 comprised 13 patients with cryptogenic cirrhosis, of whom 10 were men, their ages ranging from 46 to 70 (mean 62) years. Group 4 comprised seven patients with alcoholic cirrhosis and one with granulomatous liver disease of unknown aetiology. Six were men and their ages ranged from 37 to 62 (mean 51) years.

A diagnosis of keratoconjunctivitis sicca was made if there was less than $10 \mathrm{~mm}$. moistening of the filter paper during Schirmer's type I and II tests together with corneal or conjunctival staining with rose bengal. Xerostomia was diagnosed if the total saliva collection after chewing paraffin wax or gum for 10 minutes was less than $10 \mathrm{ml}$.

A sialogram was taken in five cases. Labial salivary gland biopsy specimens were obtained in five patients, and these were graded histologically according to the criteria of Chisholm and Mason (1968). Rheumatoid arthritis was diagnosed on the basis of the criteria of the American Rheumatism Association (Ropes et al., 1958).

\section{Results}

\section{Presence of Sjögren's Syndrome}

Group 1.-Keratoconjunctivitis sicca was detected in 10 cases $(42 \%)$. Xerostomia was present in nine of them and two had a history of parotid enlargement. Sialectasis was confirmed by a sialogram in two patients. The three labial biopsies performed showed grade four lymphocytic infiltration. Only one patient had rheumatoid arthritis. Two other cases had definite staining with rose bengal, but lacrimation and salivary flow were normal. It is likely that these patients have incipient keratoconjunctivitis sicca (Holm, 1949).

Group 2.-Keratoconjunctivitis sicca was detected in 13 patients $(72 \%)$. Xerostomia was present in 11 of them, and one had a history of parotid enlargement. Sialectasis was confirmed by a sialogram in two cases. Of the two labial biopsies performed, one showed grade 3 and the other grade 4 lymphocytic infiltration. One patient had rheumatoid arthritis.

Group 3.-Keratoconjunctivitis sicca was detected in five cases $(38 \%)$, two of whom also had xerostomia. None of the patients had parotid enlargement or rheumatoid arthritis.

Group 4.- Keratoconjunctivitis sicca, xerostomia, and rheumatoid arthritis were not detected. One patient with alcoholic cirrhosis had parotid enlargement.

\section{Immunological Investigations}

The results of the immunological investigations are shown in the Table, in which each of the four groups have been subdivided into those cases with and those without sicca complex. The autoantibody and immunoglobulin abnormalities present in each group correspond to those commonly found in each liver disease (Doniach et al., 1966; Hobbs, 1970). Autoantibodies were more common in the patients with 
Immunological Investigations in the Four Groups of Patients with Liver Disease

\begin{tabular}{|c|c|c|c|c|c|c|c|c|c|c|c|}
\hline & & \multicolumn{2}{|c|}{1} & \multicolumn{2}{|c|}{2} & \multicolumn{2}{|c|}{3} & \multicolumn{2}{|c|}{ Total } & \multicolumn{2}{|c|}{4} \\
\hline & & $\mathbf{a}$ & b & $\mathbf{a}$ & b & $\mathbf{a}$ & b & $\mathbf{a}$ & b & $\mathbf{a}$ & b \\
\hline $\begin{array}{l}\text { Autoantibodies: } \\
\text { No. tested } \ldots \\
\text { Rheumatoid factor } .0 \\
\text { Antinuclear antibody } \\
\text { Smooth muscle antibody } \\
\text { Mitochondrial antibody } \\
\text { Immunoglobulins: } \\
\text { No. tested } \\
\text { IgG (>175 M.N.A.\%) } \\
\text { IgA (>175 M.N.A.\%) } \\
\text { IgM (>175 M.N.A. \%) } \\
\text { "Monomer IgM". .. }\end{array}$ & $\begin{array}{l}\cdots \\
\because \\
\therefore \\
\cdots \\
\therefore \\
\therefore\end{array}$ & $\begin{array}{r}10 \\
6 \\
2 \\
4 \\
2\end{array}$ & $\begin{array}{r}14 \\
5 \\
7 \\
4 \\
3\end{array}$ & $\begin{array}{r}13 \\
6 \\
4 \\
3 \\
13\end{array}$ & $\begin{array}{l}5 \\
4 \\
0 \\
1 \\
5\end{array}$ & $\begin{array}{l}4 \\
1 \\
3 \\
1 \\
0\end{array}$ & $\begin{array}{l}8 \\
3 \\
2 \\
2 \\
0\end{array}$ & $\begin{array}{r}26 \\
16 \\
9 \\
15 \\
2\end{array}$ & $\begin{array}{r}21 \\
11 \\
7 \\
15 \\
0\end{array}$ & $\begin{array}{l}\mathbf{0} \\
0 \\
0 \\
0 \\
0 \\
0 \\
\mathbf{0} \\
\mathbf{0} \\
\mathbf{0} \\
\mathbf{0} \\
\mathbf{0}\end{array}$ & $\begin{array}{l}8 \\
3 \\
1 \\
0 \\
0\end{array}$ \\
\hline
\end{tabular}

$a=$ With sicca complex. $\quad b=W$ ithout sicca complex.

sicca complex, but this increased incidence was not statistically significant and no specific pattern was diagnostic of the disorder.

The serum immunoglobulin concentrations expressed as a percentage of the mean normal adult (M.N.A.\%) are shown in Fig. 1 (Hobbs, 1970). The presence of sicca complex is not related either to the levels or to the actual class of immunoglobulin raised.

\section{Liver Function}

The results of liver function tests are summarized in Fig 2. No significant difference was detected in the levels of aspartate aminotransferase alkaline phosphatase, bilirubin, albumin, and total globulin in those patients with and those without sicca complex.

\section{Discussion}

The sicca complex was present in $51 \%$ of the patients with autoimmune liver disease in this series. A systematic investigation of patients with liver disease for the presence of Sjögren's syndrome has not been recorded previously, but sporadic reports have suggested that the two disorders may be associated. Krook (1961) found five cases of the sicca complex in a series of nine patients with cirrhosis. Doniach et al. (1966) noted the presence of Sjögren's syndrome in two cases of primary biliary cirrhosis and one of active chronic hepatitis in a large series of patients with autoimmune liver disease.

Liver abnormalities are often found in patients with

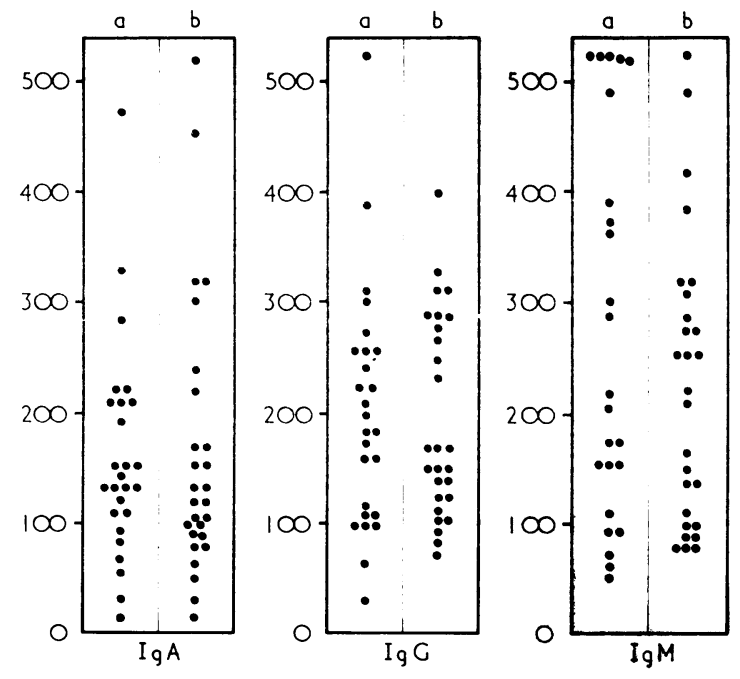

Frg. 1.- Immunoglobulin levels in patients with liver disease. The levels are expressed as a percentage of mean normal adult (M.N.A.\%). (a) With
sicca. (b) Without sicca. The two patients with monomer IgM are not
included.
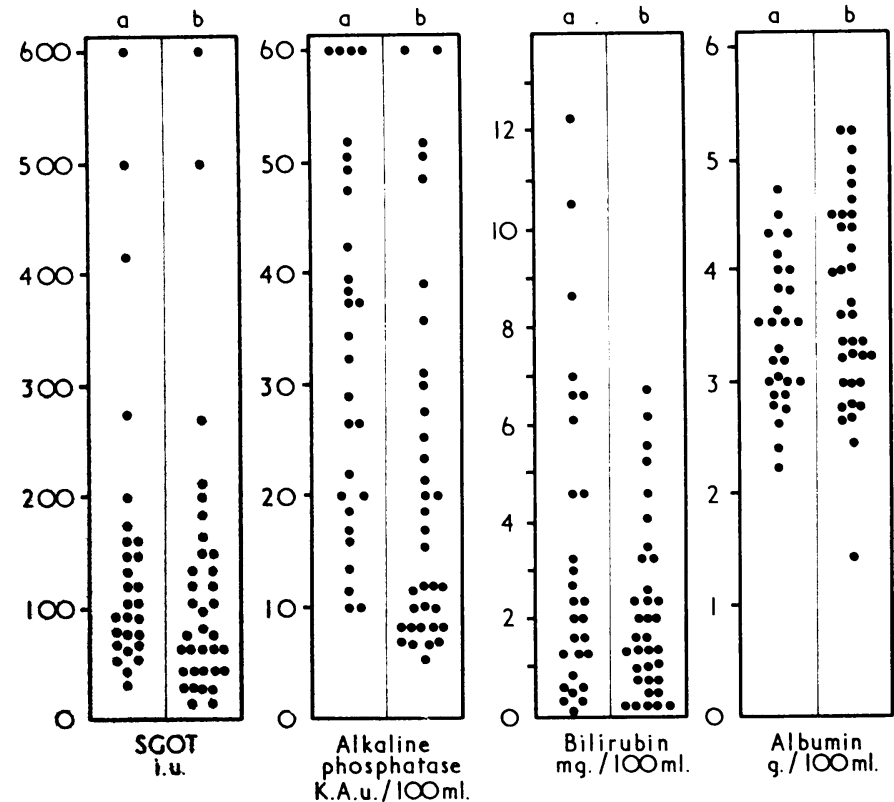

Fic. 2.-Liver function tests in cases with (a) and without (b) sicca complex.

Sjögren's syndrome. Cristiansson (1954) was the first to suggest that there was an association between corneal changes and impaired liver function, and McLenachan (1956) considered that hepatic dysfunction was present in most cases of keratoconjunctivitis sicca. Bloch et al. (1965) found hepatomegaly in $13(25 \%)$ of their patients, three of whom had an abnormal bromsulphthalein retention. Thirteen other cases in this series had abnormal liver function tests. Vanselow et al. (1963) detected hepatomegaly in $18 \%$ of their patients with Sjögren's syndrome. Cirrhosis was diagnosed in $15 \%$ of the patients with Sjögren's syndrome reported by Bertram and Halberg (1965). Whaley et al. (1970) found evidence of hepatocellular disease in $6 \%$ of their cases with sicca complex, but only those patients with mitochondrial antibody were investigated. This may explain the low prevalence of liver disease in their series, as in the present study 11 cases $(40 \%)$ who had both disorders did not have mitochondrial antibody in the serum.

McLenachan (1956) suggested that hepatic dysfunction was responsible for keratoconjunctivitis sicca due to an inability of the liver to utilize vitamin A. In our series, however, apart from deficient lacrimation there were no other clinical signs, nor, in those studied, was there biochemical evidence of vitamin A deficiency. There was no difference in the degree of hepatocellular damage between the patients in group 4 and those in the other three groups. The sicca complex was not detected in the eight patients in group 4 , which suggests that the components of Siögren's syndrome may occur commonly only in patients with liver disease thought to be due to autoallergic mechanisms and are not related to the degree of hepatocellular dysfunction.

Autoimmune liver disease and the sicca complex are associated with similar immunological abnormalities. Hyperglobulinaemia and non-organ-specific autoantibodies are frequently detected in both disorders, and impairment of the delayed hypersensitivity mechanism has been noted in both Sjögren's syndrome (Leventhal et al., 1967) and primary biliary cirrhosis (Fox et al., 1969). Probably immunological mechanisms are concerned in the pathogenesis of both disorders, and the liver and corneal abnormalities may be only part of a systemic disorder capable of affecting many organs (Mason and Golding, 1970). All the patients in groups 1-3 in this series had immunological abnormalities, but it was not possible to identify those cases with the sicca complex on the basis of either the immunoglobulin results or the pattern 
of autoantibodies detected. Further clinical and experimental studies are required to determine the precise mechanisms concerned in the pathogenesis of these two disorders.

We wish to thank the physicians at the London, St. Bartholomew's, and the Southampton General Hospitals, in particular Dr. A. Dawson and Dr. J. Bamforth, for permission to study patients under their care; Mr. J. Corrigan for assistance with the ophthalmological investigations; Professor I. Doniach and Dr. A. Stansfield for reviewing the histological sections; and Dr. G. Franglen and Mr. R. Lloyd, for assistance with the immunological investigations.

The work was supported by funds from the Medical Research Council (A.M.S.M.), the London Hospital Free Funds (P.L.G.), and a grant from the Governors of St. Bartholomew's Hospital (R.B.).

Requests for reprints to Dr. P. L. Golding, Division of Medicine, the London Hospital, Whitechapel, London E.1.
REFERENCES

Bertram, U., and Halberg, P. (1965). Acta Allergologica, 20, 472

Bloch, K. J., Buchanan, W. W., Wohl, M. J., and Bernim, J. J. (1965) Medicine, 44, 187.

Chisholm, D. M., and Mason, D. K. (1968). Journal of Clinical Pathology, 21,656 .

Cristiansson, J. (1954). Acta Ophthalmologica, 32, 161.

Doniach, D., Roitt, I. M., Walker, J. G., and Sherlock, S. (1966). Clinical and Experimental Immunology, 1, 237.

Doniach, D., and Walker, J. G. (1969). Lancet, 1, 813.

Fox, R. A., James, D. G., Scheuer, P. J., Sharma, O., and Sherlock, S. 1969). Lancet, 1, 959.

Heaton, J. M. (1959). British Medical fournal, 1, 466.

Hobbs, J. R. (1970). British Fournal of Hospital Medicine, 3, 669.

Holm, S. (1949). Acta Ophthalmologica, Suppl. No. 33, p. 1.

Krook, H. (1961). Acta Medica Scandinavica, 169, 713

Leventhal, B. G., Waldorf, D. S., and Talal, N. (1967). fournal of Clinical Investigation, 46, 1338.

McLenachan, J. (1956). Trunsactions of the Ophthalmological Society of the United Kingdom, 76, 413.

Mason, A. M. S., and Golding, P. L. (1970). British Medical fournal, 3, 143

Ropes, M. W., Bennett, G. A., Cobb, S., Jacox, R., and Jessar, R. A. (1958). Bulletin on Rheumatic Diseases, 9,175 .

Sjögren, H. (1933). Acta Ophthalmologica, Suppl. No. 2, p. 1

Vanselow, N. A., Dodson, V. N., Angell, D. C., and Duff, I. F. (1963). Annals of Internal Medicine, 58, 124

Whaley, K., et al. (1970). Lancet, 1, 861.

\title{
Controlled Trial of Oxprenolol and Practolol in Hypertension
}

\author{
A. W. D. LEISHMAN, ${ }^{*}$ D.M., F.R.C.P. ; J. L. THIRKETTLE, $†$ M.B., M.R.C.P. ; B. R. ALLEN, $\ddagger$ M.B., CH.B., M.R.C.P.
} R. A. DIXON, $\subseteq$ B.SC.

British Medical fournal, 1970, 4, 342-344

\begin{abstract}
Summary : In controlled trials of the beta-adrenergic blocking drugs oxprenolol and practolol in hypertension both drugs were well tolerated without side effects and caused statistically significant non-postural reduction of blood pressure. In less than half the patients on either drug the reduction of blood pressure was clinically adequate. No attempt was made to compare the two drugs.
\end{abstract}

\section{Introduction}

It is established that beta-adrenergic blocking drugs have blood-pressure-lowering action, but opinions on the value of propranolol, the most widely used drug of this character, in the management of hypertension have varied. Paterson and Dollery (1966), Humphreys and Delvin (1968), and Richardson et al. (1967) were unenthusiastic, but Prichard and Gillam (1969) and Zacharias and Cowen (1970) reported favourably. The hypotensive action of propranolol may be due to reduction of sympathetic cardiac drive and cardiac output, there being no alteration in peripheral vascular resistance (Frolich et al., 1968). An advantage of this is that the drug causes neither postural nor exertional hypotension. In certain circumstances, however, propranolol may provoke heart failure and bronchospasm.

Both practolol (4-(2-hydroxy-3-isopropylaminopropoxy)acetanilide; Eraldin) and oxprenolol (1-(o-allyloxyphenoxy)-3isopropylamino-2-propanol hydrochloride; Trasicor) are beta-adrenergic blocking drugs which are relatively cardioselective, showing much less activity than propranolol in blocking other beta-receptors. Practolol does not show the quinidine-like effect of propranolol, but its other cardiac

- Consultant Physician, Royal Infirmary, Sheffield.

† Senior Medical Registrar, Royal Infirmary, Sheffield. (Now Consultant Physician, Crawley Hospital, Crawley, Sussex.

‡ Medical Registrar, Royal Infirmary, Sheffield.

Statistician, Department of Preventive Medicine, University of Sheffield. effects are similar, slowing the heart rate and reducing cardiac output, most pronounced on exercise. In its action on the heart, however, practolol appears to have about $40 \%$ of the potency of propranolol (Barrett et al., 1968). Oxprenolol appears to differ in one important respect from propranolol; for Wilson et al. (1968) showed that prolonged oral administration, though having varying effect on cardiac output, causes a noticeable increase in stroke volume, a property which might give it an advantage over propranolol.

This paper describes a small controlled trial of each of these drugs in the treatment of hypertensive patients.

\section{Methods}

Forty-eight patients wiere considered suitable for the trial, and after full explanation they agreed to take part; 24 were given oxprenolol and 24 received practolol. Allocation to either drug was by random selection. All had benign essential hypertension previously untreated. Patients with diastolic pressure exceeding $124 \mathrm{~mm} . \mathrm{Hg}$, blood urea higher than $50 \mathrm{mg} . / 100 \mathrm{ml}$., heart failure, or chronic respiratory disease were not included. The blood urea, white blood count, aspartate aminotransferase, alanine aminotransferase, and airways resistance $\left(\mathrm{FEV}_{1} / \mathrm{FVC} \times 100\right)$ were recorded at the start of the trial and immediately before the double-blind phase.

Initially, patients were admitted to the ward and kep under observation without treatment until the blood pressure reached a steady level. At this point a single test dose of the drug $(10 \mathrm{mg}$. of oxprenolol or $50 \mathrm{mg}$. of practolol) was given to exclude any untoward effect. If this was tolerated the patients were started on the respective drugs, given three times daily.

Oxprenolol was supplied in 20-mg. tablets. The starting dose was $20 \mathrm{mg}$. three times daily, and this was increased on alternate days by $20 \mathrm{mg}$. (all three doses) until the diastolic blood pressure was controlled or the previously agreed maxi- 